\title{
Selecting Maritime Disaster Response Capabilities
}

\author{
Aruna Apte \\ Naval Postgraduate School \\ auapte@nps.edu \\ Keenan D. Yoho \\ Naval Postgraduate School \\ kdyoho@nps.edu \\ Cullen M. Greenfield \\ United States Navy \\ greenfc@lsd48.navy.mil \\ Cameron A. Ingram \\ United States Navy \\ cam_ingram22@yahoo.com
}

\begin{abstract}
Using a structured, qualitative evaluation schema complemented by expert rating, we evaluate the capabilities and utility of ships in the United States Navy and United States Military Sealift inventory. We find that there are specific types of vessels with significant disaster response utility and recommend a flotilla type that would be best suited for these types of operations. Utilizing an exploratory framework that evaluates three diverse disaster cases, we scale the utility of each vessel using subject matter experts. This work should be of interest to national policy-makers as well as international governing bodies and leaders of naval institutions for its recommendations on the type of ships most useful for contributing to effective disaster response. The capabilities identified in this research are found in various naval and maritime organizations throughout the world, and this work can help assist those organizations identify the types of capabilities that are most useful in the event of a disaster.
\end{abstract}

Keywords: Disaster Response, Capability, United States Navy, Humanitarian Operations 


\section{INTRODUCTION}

In the last decade, incidences of major disasters have increased significantly. In 2009, there were 335 natural disasters reported worldwide that killed 10,655 persons, affected more than 119 million others, and caused over $\$ 41.3$ billion in economic damages (Vos et al., 2009). Figure 1 shows the overall trend of disasters and damage by year. While the trend in the number of disasters reported shows an increase, it is not clear that there has been a commensurate response.

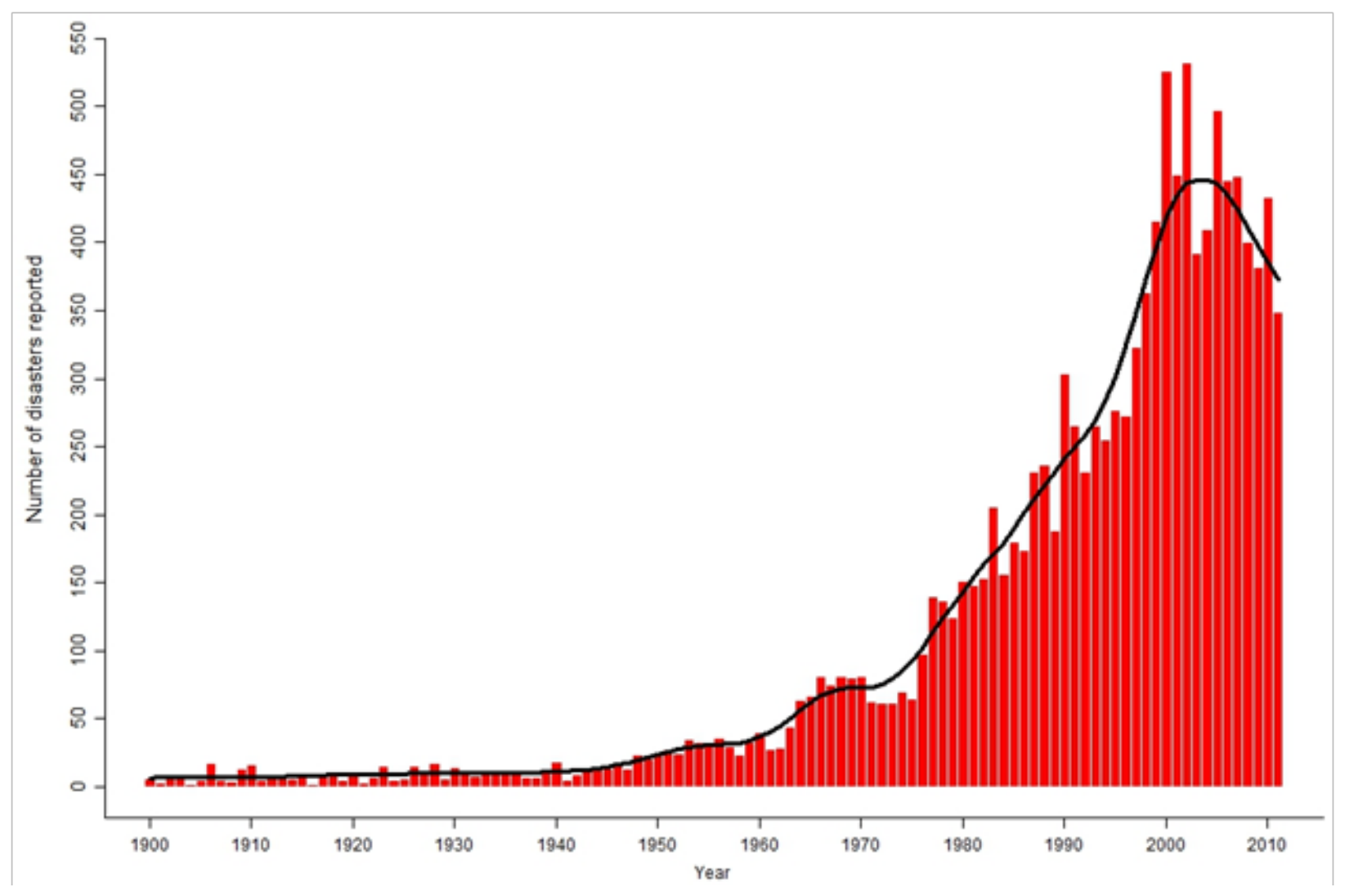

Figure 1: Natural Disasters Reported 1900-2011(EM-DAT, 2011)

Whereas matching supply to demand is an important aspect of supply chain management, disasters invariably result in conditions where both supply and demand can be extremely uncertain (Whybark, 2007) and matching is made very difficult. Webster's Dictionary defines capability as an ability to do something, the quality or state of being capable or an ability to perform actions. We, in this research, find and analyze those capabilities that lead to effective (in terms of reaching most of the affected population) and efficient (in terms of time and money) relief operations in case of disaster. We believe that understanding various organizations' abilities to match supply to demand for humanitarian operations will enrich the planning process for such relief operations, leading to efficient management of a response supply chain (Balcik et al., 2010).
The United States (U.S.) military, United Nations (UN), Red Cross, CARE, World Food Program, North Atlantic Treaty Organization (NATO), and Military and Civil Defense Assets (MCDA) are but a few of the significant players in a disaster response supply chain. In this study, we examine the unique capabilities and assets of the U.S. Navy (USN) and Military Sealift Command (MSC) to determine which maritime military assets are best suited for disaster response.

\subsection{Motivation}

On November 15, 2007, Bangledesh was struck by Cyclone Sidr, which caused over 10,000 deaths and more than US\$450 million in damages. In response, the USN decided to send one of its guided missile destroyers (DDGs), which was in the vicinity. Due 
to the gradual slope of the ocean floor along the Bangledesh coastline, which creates a relatively shallow draft, the DDG could approach no closer than 25 miles from the shoreline, which was out of the visibile range. Additionally, the DDG was not outfitted with a helicopter, could not produce enough water to supply victims or hospitals ashore, and did not have extra food or medical supplies to provide the disaster victims. In short, this ship was unable to provide tangible relief to the devastated area, an example of a misplaced asset leading to underutilized capability.

Based on United States Agency for International Development (USAID) fact sheets and Center for Naval Analysis, U. S. forces have been diverted from original mission 366 times for humanitarian assistance as opposed to 22 times for combat from 1979 to 2000 . The USN may send assets that are able to reach an affected area quickly, but the effort serves no purpose if the vessels sent are not suitable for the task at hand. Such examples illustrate that in order to become more effective in humanitarian assistance and disaster relief (HADR) operations we need to understand which assets may contribute the greatest benefit when responding to specific disasters. This was our motivation for this research since the prevailing assumption that the closest asset is the best asset to deploy will not necessarily lead to a suitable or effective utilization of resources. It is evident that although the USN has contributed many ships to past disaster relief efforts, not all are equally capable of providing effective relief nor should all be sent to respond. It is not a question of providing the relief but what capabilities exist to perform such humanitarian operations is of consequence in order to achieve efficient and effective relief. Our research objective is an effort to understand the USN's capability to meet the perceived demand of an affected population during a disaster and analyze the capabilities of all major assets in the USN and MSC inventory.

\subsection{Contribution of Our Research}

We studied the past responses of the USN not only to understand the capabilities but also to analyze whether these capabilities have been utilized to the best of their ability. The response to the earthquake in Haiti, Hurricane Katrina, and the Indian Ocean tsunami are but three among many contributions made by the USN to natural disasters over the past decade. With a large number of the world's population living in close proximity to the coastline, the
USN's ability to traverse and deploy large quantities of relief from the sea is a valuable capability during a disaster relief operation and helps to reduce the gap of pain, which has been described as the time between the demand for aid and the time in which the aid is provided (Cuculo, 2006).

As defense budgets for some nations, to include the U.S., become constrained, it is increasingly essential that ships, aircraft, and land-based systems are adaptable for many uses, to include those that do not directly involve warfare. Current literature in the public sector (Xinhua, 2013; Miles, 2011; Guilloux, 2011; Moroney et al. 2013) illustrates the need for understanding the capabilities of organizations involved in disaster response. However, to our effort we could not identify any scholarly articles on the specific topic discussing the capabilities of organizations involved in humanitarian assistance and disaster relief. We believe, this is a new but critical topic in the field of humanitarian logistics and therefore our analysis is of value to decision makers who must determine capital equipment acquisitions that will shape naval forces that must deploy across a wide spectrum of crises. This is of special note since the U.S. Department of Defense has articulated a broad strategic vision to influence foreign policy and achieve defense goals through operations other than war, in particular, by employing HADR. We propose an "HADR flotilla" that can be better utilized for HADR operations as a step in the right direction. There has been research that looks at the USN's role in humanitarian assistance (Freedberg, 2012); however, ours is the first study of its kind that links the strategic considerations of determining what types of missions will be included as part of a security strategy (such as those that include HADR operations) and then connecting those strategic decisions to the operational options available as a result of asset purchases that took place in the past. Further, our work informs future asset purchase decisions with respect to which vessel types serve multiple uses (warfare and non-warfare missions) that contribute to national security.

\section{UNDERSTANDING THE SUPPLY AND DE- MAND OF A NATURAL DISASTER}

In order to provide appropriate humanitarian support, an organization must assess the needs of the affected population, study its own capabilities to provide relief, and match the needs of the affected population with their own native capabilities. From 
the operations perspective, there have been many scholarly articles written that describe the activities that occur during disaster relief operations (e.g., Apte, 2009; Yi and Ozdamar, 2007; Hale and Moberg, 2005; Pettit and Beresford, 2005; Barbarosoglu et al., 2002; Baker et al., 2002; Day et al., 2012.

In many disasters, supply does not necessarily follow the demand. What is needed and precisely when and where it is needed may be unknown. Further, the capabilities and scope of the supply of disaster responders may be unknown to those in the affected disaster area. The uncertainty associated with both the demand for and supply of disaster assistance frequently leads to a mismatch of goods and/or services in quantity, type, or both (Apte, 2009; McCoy, 2008).
To better understand the nature of demand and supply for aid, we analyzed different types of disasters to uncover and describe a generalized set of needs (or demand), which we call disaster traits. Some of these needs will be met by non-military organizations, and some by military organizations. On the supply side, our focus is on the military organization. We specifically study the role of the USN in the past three disasters to understand how demand was met-not through just one asset, such as a ship, but through a portfolio of assets that constitute the force structure of the USN. We also wished to understand the timing of demand and supply for disaster aid. Through our analysis of the USN response to three major disaster events, we were able to determine the "on-scene" arrival of each ship and build an illustration of the cumulative supply of assistance over time.

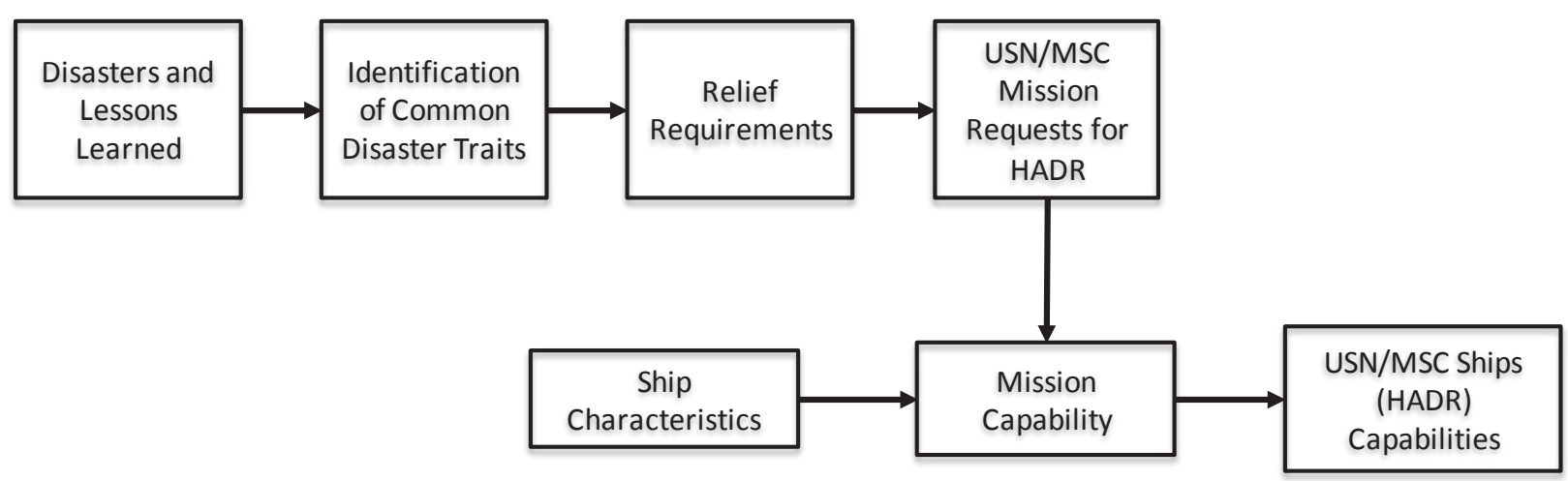

Figure 2a. Flow Chart of Demand and Supply: USN

Figure 2a shows that every disaster has certain traits that generate USN and MSC mission requests for ships, leading to a requirement for certain mission capabilities of those ships. All ships have specific characteristics that make them suitable for certain types of requirements. Once the requirements are known, then these demands-as well as the supply of ship characteristics that can meet those demands - can be matched.

Disasters and war share several traits, such as a high number of deaths and injuries, population dispersion, facility destruction and loss of common goods (such as a freshwater supply), and a need for medical facilities and personnel. Both the U.S. military and non-military organizations bring assets, skills, and capabilities to a humanitarian crisis. The competencies and capacities of each are far from homogeneous. Identification of the specific competencies and capabilities that are core to the types of organizations will clarify who, what, and when relief is brought to the crisis. In this study, we perform the analysis for one such organization. Though the specific methodology is domain-specific in details we describe an overall process similar to ours of evaluating the capabilities of resources of the corresponding organization in Figure $2 b$. Such process analysis will yield what the capabilities and competencies of that organization are and whether they are utilized efficiently. 


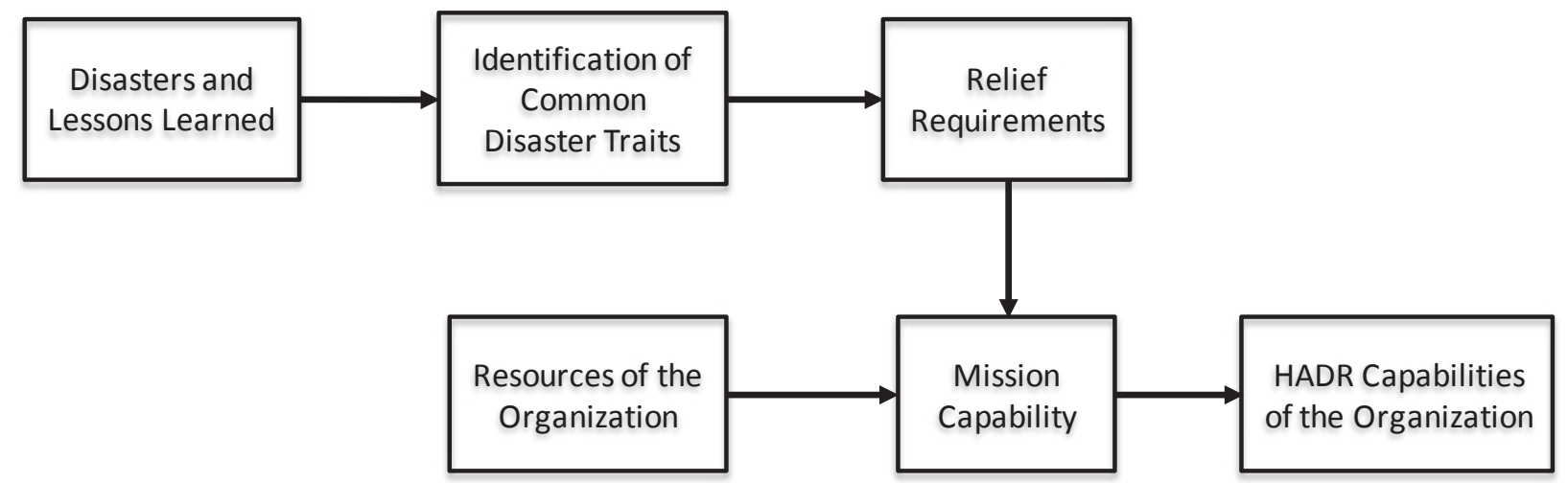

Figure 2b. Overall Flow Chart of Demand and Supply

The remainder of the paper is structured as follows. In Section 2, we describe the demand for resources during a disaster by relating a set of common disaster traits that drive relief requirements. In Section 3, through our data collection, we describe the capabilities of specific USN vessels and the mission requests that each is able to fulfill. In Section 4, we observe and identify those vessels that are most capable of fulfilling specific demands and requirements during a disaster. The fulfillment process has two dimensions: (1) the supply of a needed resource for the demand and (2) the timing of the fulfillment of that demand. In Section 5, we offer our analysis about how demand for disaster relief may best be met by specific types of USN assets based upon their capabilities and limitations. In the last section, we conclude the article and describe possibilities for future research.

\section{THE DEMAND}

We collected and analyzed data on the scale and scope of the following disasters: the 2004 tsunami in the Indian Ocean, the 2005 Hurricane Katrina, and the 2010 earthquake in Haiti. The primary reasons we selected these three disasters was because (1) the USN provided significant assistance and relief in each instance, (2) the disasters offered enough similarities and differences to make interesting contrasts from a case perspective, and (3) all three were ma- jor disasters that occurred within the last decadetherefore, data were readily available.

Table 1 shows the similarities and differences between each disaster, which resulted in different demand signals for search and rescue, transfer of affected members of the population, triage facilities, and critical supplies such as freshwater. For each of the three events discussed in this research, we first developed a list of common disaster traits.

\subsection{Disaster Traits}

The Indian Ocean tsunami of 2004 was the result of an earthquake that measured 9.1 in magnitude on the Richter scale; at the time, it was the fourth-largest earthquake worldwide since 1900. The tsunami that occurred in the aftermath struck more than a dozen countries. Indonesia experienced most of the damage, resulting in broad destruction of many elements of critical infrastructure. The coastal highway on the island of Sumatra was completely destroyed, making many damaged areas inaccessible to land-based aid workers (Elleman, 2007). In Indonesia, the tsunami destroyed more than $25 \%$ of Aceh Province's villages, along with much of the transportation and communications infrastructure. Other countries affected by the tsunami lost all electric power production capability. Debris along the coast of Indonesia as a result of the tsunami presented navigation challenges to ships because of uncertainty in the location of the coastline. 
Table 1. Effects of the Indian Ocean Tsunami, Hurricane Katrina, and the Haiti Earthquake

\begin{tabular}{|c|c|c|c|}
\hline Disaster & 2004 Indian Ocean Tsunami & 2005 Hurricane Katrina & 2010 Haiti Earthquake \\
\hline \multicolumn{4}{|l|}{ Affected Area } \\
\hline $\begin{array}{c}\text { Location } \\
\text { Scope } \\
\text { Infrastructure }\end{array}$ & $\begin{array}{c}\text { Coastal } \\
\text { Dispersed in many countries } \\
\text { Inadequate }\end{array}$ & $\begin{array}{c}\text { Coastal } \\
\text { Localized in one country } \\
\text { More than adequate }\end{array}$ & $\begin{array}{c}\text { Coastal } \\
\text { Localized in one country } \\
\text { Substandard or non-existent }\end{array}$ \\
\hline $\begin{array}{c}\text { Economic } \\
\text { Development }\end{array}$ & Underdeveloped or Developing & Developed & Underdeveloped \\
\hline Speed of Onset & Sudden and then Imminent & Imminent & Sudden \\
\hline \multicolumn{4}{|l|}{ Consequences } \\
\hline Deaths & $>227,000$ & $>1,700$ & $92,000-220,000$ estimated \\
\hline Injured & $>500,000$ & $>2,000$ in New Orleans alone & 250,000 \\
\hline Missing & $>2,000,000$ (summary of initial reports) & $>12,000$ reported & 20,000 \\
\hline Displaced & $>1,500,000$ & $>1,000,000$ in gulf coast states & $1,100,000$ \\
\hline \multicolumn{4}{|l|}{ USN Involvement } \\
\hline $\begin{array}{c}\text { Number of Ships } \\
\text { Deployed by USN }\end{array}$ & 29 & 34 & 31 \\
\hline Days of Assistance & 81 & 42 & 72 \\
\hline
\end{tabular}

(VanRooyen and Leaning, 2005; CRS, 2005; Louisiana Department of Health and Hospitals, 2006; NOAA Public Affairs, 2007; Plyer, 2010; Wooldridge, 2010)

Hurricane Katrina struck Louisiana's coastline on August 29, 2005. Hurricane Katrina is recognized as the most costly hurricane ever to strike the United States, with an estimated $\$ 135$ billion in damage to the gulf coast states (Plyer, 2010). As a result of Hurricane Katrina, more than three million people were left without power and thousands without freshwater as a result of broken water mains. More than $80 \%$ of New Orleans was underwater on August 31, 2005, to include the area's international airport. Highways throughout the Gulf of Mexico region were closed due to flooding, and there was considerable damage to the oil and fishing industries as a result of lost boats and rigs blown from their fixed locations.

The earthquake that impacted Haiti on January 12, 2010, was 7.0 in magnitude and lasted 35 seconds. The earthquake caused significant damage to Haiti's infrastructure and resulted in many deaths and serious injuries (Aymat, 2010). The Haiti earthquake destroyed all five medical facilities around Portau-Prince as well as portions of the international airport. Most of the Port-au-Prince communication infrastructure and roadways as well as the seaport were destroyed during the immediate rescue operations. Debris from fallen buildings presented a significant obstacle to rescue teams attempting to reach those still trapped beneath the rubble in the immediate aftermath. The collapse of port docks and cranes in Haiti presented navigation challenges to ships because of uncertainty in the location of the coastline.
We found that all three disasters shared common traits and that these traits were also observed in many disasters catalogued by the International Disaster Database (EM-DAT; EM-DAT, 2011). The devastating effects of these disasters and the lessons learned from them clue us in on the possible needs of the affected community. The destruction of critical infrastructure, public goods (such as water), and critical facilities (such as hospitals) was apparent in each of the disasters. Some of the basic traits that these disasters have in common include a high number of deaths and injuries, population dispersion, homelessness, and a high number of missing persons, facility destruction and loss of common goods such as a freshwater supply, a need for medical facilities and personnel, and volunteers. These disaster traits induce the demand for relief. We list these in the first column of Figure 3. This identification is the first step in understanding the needs or demands of the affected community in an attempt to match the supply of relief with this demand (Figure 2a).

\subsection{Relief Requirements}

The disaster traits identified lead to specific relief requirements. Although not exhaustive, we identify those relief requirements that correspond to the disaster traits in the second column of Figure 3. In this figure, we match a specific disaster trait with various relief requirements. 
Disaster Traits

\begin{tabular}{|l|l|}
\hline Large number of deaths and injuries \\
\hline $\begin{array}{l}\text { Population dispersion, homelessness, and large } \\
\text { number of missing persons }\end{array}$ \\
such as fresh water, food, and medical supplies \\
\hline $\begin{array}{l}\text { Need for medical personnel, facilities, and } \\
\text { volunteers } \\
\text { such as airports, seaports, railroads, and roads }\end{array}$ \\
$\begin{array}{l}\text { Large amounts of debris and destroyed } \\
\text { buildings }\end{array}$
\end{tabular}

Figure 3. Basic Disaster Traits and Relief Requirements

For example, search and rescue missions are initiated as a result of missing persons; therefore, we identify search and rescue as a critical relief requirement. Homelessness and population dispersion require personnel to be transferred from unstable to stable locations. Injuries, combined with a shortage of medical supplies and clinicians, generate a requirement for trauma teams supported by triage tents and operating rooms. Damage to infrastructure such as water pipes often results in freshwater scarcity. The destruction of critical facilities and transportation infrastructure such as airports and public administration buildings generates a need for the construction of temporary structures to carry out the essential humanitarian operations. Because debris can hamper the speed and effectiveness of the relief effort, there is often a requirement for engineering equipment such as heavy earthmoving machinery. In addition to these relief requirements, there is a need for a strong and able workforce unaffected by the outcome of the disaster to conduct cleanup operations.

\section{THE SUPPLY}

We have discussed the needs in case of a disaster. We now describe the USN's capabilities-based on its past-in fulfilling some of these needs on the supply side. The USN has two basic classes of ships available to conduct missions: combatant ships and noncombatant ships. Combatant ships are part of the USN, and noncombatant ships are part of the MSC. The MSC has a rather unique reporting structure in its chain of command in that it reports to the commander of the USN Fleet Forces Command for Navy-specific missions, to the commander of the U.S. Transportation Command for the movement of Department of Defense items, and to the assistant secretary of the Navy for research, development and acquisition for anything related to procurement. In order to develop a comprehensive understanding of the capabilities of USN and MSC ships, we examined source documents on ships from multiple USN and MSC publications as well as the historical records of disasters and the response to those disasters by both organizations. Data supporting our analysis of the USN response to the three disasters was obtained from operational commander historical logs and archives, operational chronological records, operational orders, deployment orders, and daily situation reports. The result of our analysis is a detailed understanding of the specific characteristics attributable to each vessel in the USN and MSC inventory as well as the relative degree to which these characteristics contribute to effective disaster response. 


\subsection{Mission Requests}

The measure of a ship's capability to conduct a specific HADR mission set is derived from the vessel's specific characteristics. The USN and MSC have many different types of vessels with different capabilities that are selected through a mission request process generated by the officers of the Navy. In order to understand which ships are better suited for HADR operations, we first discuss the different types of missions that operational commanders may be requested to conduct. Mission requests may include aircraft support, amphibious landing, or freshwater production, as well as the ability to conduct towing or salvage operations.

The specific characteristics of all USN and MSC vessels were drawn from public databases such as Jane's Fighting Ships (Jane's, 2010), the MSC handbook (MSC, 2010), and the online Navy Fact Files (www.navy.mil/navydata/fact.asp). These characteristics include speed, draft, lift capacity, number of onboard personnel, freshwater-making capacity, storage space, and other traits that enable a ship to support one of the identified HADR missions

\subsection{USN and MSC Ship Capabilities}

In this subsection, each ship class and its HADRrelated characteristics are broken down by platform, to include the various classes within the platform. The characteristics analyzed include only those characteristics applicable to HADR operations.

Not all of the MSC's vessels are government owned nor are they all in a ready status. The MSC is capable of leasing commercial ships and maintains its own forces as well. A general breakdown of MSC vessel types includes the following: naval fleet auxiliary forces, which supply USN ships at sea; special mission ships, which perform a variety of missions; ships that enable strategic placement of military supplies in key areas of the ocean (defined as prepositioning); and sealift ships, which provide ocean transportation for equipment and supplies (MSC, 2010).

For classification purposes, we have divided MSC ships according to their program designation. The most beneficial aspects of the MSC fleet are the ability to carry large amounts of cargo to a disaster area and the ability to provide significant medical support. Another benefit of MSC ships relevant to HADR missions is that some of them are self-sustaining, in terms of their capability of on-loading and off-loading cargo without the assistance of outside equipment.

Landing craft serve as the waterborne transportation link between amphibious platforms and the shore. In HADR operations, landing craft play the critical role of getting supplies, cargo, and personnel to and from the shoreline and supporting ships. USN landing craft were not designed for HADR operations, yet they are valuable assets that are capable of supporting the mission because of their lift capacity, draft, speed, and range.

When considering specific vessels, a key facet of their capability is the seaborne aircraft. Seaborne aircraft include all helicopters and fixed-wing aircraft that may be utilized by USN and MSC ships. Among the fixed-wing aircraft the USN has in its fleet, only the MV-22 Osprey was considered for this study. It is important to note that most military fixed-wing aircraft that play any significant role in HADR operations are characteristically too large to land onboard any USN or MSC vessel and therefore play no role in determining the usefulness of different vessels. Aircraft were evaluated in terms of the capabilities they contributed to their sea-basing platform; these capabilities were primarily lift capability, personnel transportation capability, and range.

We compared the capabilities of USN and MSC platforms to basic mission requests to identify which USN and MSC vessels are best suited to satisfy the relief requirements. We evaluated the relative utility of each vessel type using ordinally scaled ratings, which are assigned by USN surface warfare officers. These ratings are based on similar principles as the color-coded operational readiness of a ship (CNIC, 2012). Our ordinal ratings have three values (instead of color coding for understanding) indicating whether a ship has "little to no capability" $(\bigcirc)$, "some capability" (1), or "significant capability" (-) to accomplish a specific mission request. The three rating values for each of the capabilities for HADR mission requests and their operational definitions are given in Table 2 . 
Table 2. Capability Parameter Definitions for HADR Missions 4.3 USN and MSC Ship Platforms

\begin{tabular}{|c|c|c|c|}
\hline & & & Capability Rating Defnition \\
\hline \multirow{3}{*}{\multicolumn{2}{|c|}{ Aircraft support }} & O & No embarked helo; unable to support helicopter operations \\
\hline & & 0 & Single helo embarked; able to support the majority of helo platforms \\
\hline & & & Multiple helos embarked; able to sustain multiple flight operations simultaneously \\
\hline \multirow{3}{*}{\multicolumn{2}{|c|}{ Landing Craft support }} & O & No ability to support landing craft \\
\hline & & 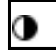 & Some ability to support landing craft \\
\hline & & & Landing craft embarked; able to load / off load cargo and store amphibious vehicles \\
\hline \multirow{3}{*}{\multicolumn{2}{|c|}{ Search and Rescue (SAR) }} & 0 & No embarked helo; unable to efficiently conduct SAR missions \\
\hline & & (1) & Single embarked helo with communication equipment and night vision \\
\hline & & 0 & Multiple helos embarked with communication equipment and night vision \\
\hline Dry goods storage & \multirow{6}{*}{ 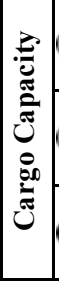 } & & \multirow{2}{*}{ No ability to store goods beyond current ship crew use } \\
\hline Refrigerated goods storage & & & \\
\hline Fresh water storage & & \multirow{2}{*}{ ( } & \multirow{2}{*}{ Ability to store supplies beyond ship crew's use } \\
\hline Roll On Roll Off & & & \\
\hline Fuel storage $\&$ dispensation & & & \multirow{2}{*}{ Ability to store and trans fer large quantities of supplies } \\
\hline Self-s ufficient & & & \\
\hline \multirow{3}{*}{\multicolumn{2}{|c|}{ Personnel transfer }} & $\mathrm{O}$ & No ability to support personnel transfer; slow speed vessel with deep draft \\
\hline & & $(1$ & Ability to support personnel transfer for $15+$ personnel \\
\hline & & 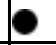 & High speed, shallow draft vessel with ability to transport $30+$ personnel per voyage \\
\hline \multirow{3}{*}{\multicolumn{2}{|c|}{ Fresh water production }} & $\mathrm{O}$ & No ability to produce freshwater beyond shipboard usage \\
\hline & & ( & Ability to produce and transfer $>2,000$ gallons per day (gpd) beyond shipboard usage \\
\hline & & & Able to produce and transfer $>5,000$ gpd beyond shipboard usage \\
\hline \multirow{3}{*}{\multicolumn{2}{|c|}{ Personnel support }} & O & Low crew size with minimal ability to support HADR mission $(<50$ personnel) \\
\hline & & (1) & Medium size crew which can support HADR mission (51 - 200 personnel) \\
\hline & & 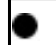 & Large crew with ability to support HADR mission ( $>200$ personnel) \\
\hline \multirow{3}{*}{\multicolumn{2}{|c|}{ Berthing capacity }} & O & Little to no excess berthing or facilities $(<30$ racks $)$ \\
\hline & & (1) & Some excess berthing and facilities (31-50 racks) \\
\hline & & 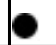 & Large number of excess berthing and facilities $(>50)$ \\
\hline \multirow{3}{*}{\multicolumn{2}{|c|}{ Medical support }} & O & No ability to conduct inpatient medical treatment; no Medical officer embarked \\
\hline & & (1) & Some medical support onboard; ability to support minor medical procedures \\
\hline & & - & Medical officer embarked; ability to perform surgeries and hold several patients \\
\hline \multirow{3}{*}{\multicolumn{2}{|c|}{ Transit speed }} & O & 0-18 knots max speed \\
\hline & & (1) & 19-24 knots max speed \\
\hline & & O & $25+$ knots max speed \\
\hline \multirow{3}{*}{\multicolumn{2}{|c|}{ Hydrographic survey }} & O & No ability to conduct hydrographic surveys \\
\hline & & (1) & Some ability to conduct hydrographic surveys to include soundings and chart building \\
\hline & & 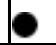 & Able to conduct hydrographic surveying, soundings and chart development \\
\hline \multirow{3}{*}{\multicolumn{2}{|c|}{ Salvage Ops }} & 0 & No ability to conduct salvage operations \\
\hline & & (1) & Some ability to conduct lift and salvage operations in shallow waters \\
\hline & & O & Able to conduct heavy lift and deep water salvage operations \\
\hline \multirow{3}{*}{\multicolumn{2}{|c|}{ Towing }} & 0 & No ability to conduct towing operations \\
\hline & & ( & Ability to conduct emergency towing operations \\
\hline & & O & Designed to conduct push, pull, or alongside towing operations \\
\hline
\end{tabular}

The USN vessels (some examples are shown in Figure 4) are displayed in four categories in Table 3: (1) nuclear-powered aircraft carriers (Nimitz and Enterprise class), (2) amphibious ships, (3) cruisers and destroyers (CRUDES), and (4) other, including the littoral combat ships, patrol craft, and mine countermeasures ships. Figure 4. Amphibious Assault Ship, 

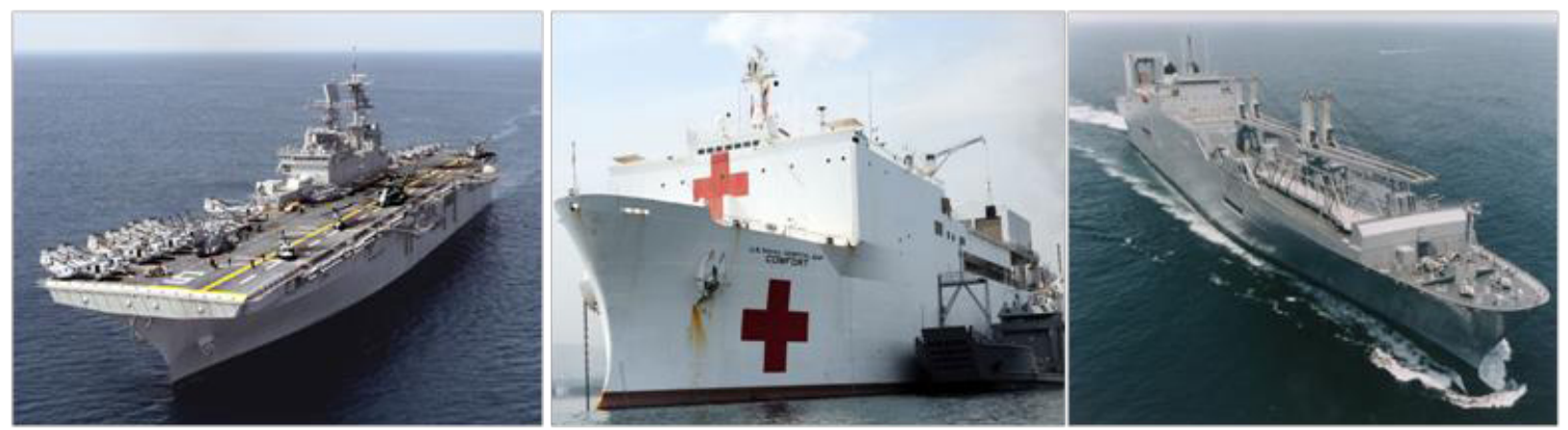

Hospital Ship, and Roll-on/Roll-off Ship

For the MSC, naval fleet auxiliary force vessels are made up of fleet replenishment oilers, dry cargo and ammunition ships, rescue and salvage ships, fleet ocean tugs, and hospital ships (see Table 4). The special mission ships are composed of a command ship, submarine tenders, ocean surveillance and survey, missile range instrumentation, and cable repair. The prepositioning ships include large, medium-speed, roll-on/roll-off vessels; maritime prepositioning ships capable of loading and unloading containerized cargo without the aid of dockside cranes; as well as accommodating roll-on/roll-off cargo such as vehicles, offshore petroleum discharge ships, breakbulk ships for non-containerized cargo, and highspeed vessels, which are high-speed catamarans capable of transporting personnel or equipment. The vessels, part of the sealift program, include large, medium-speed, roll-on/roll-off vessels; common-use tankers; dry cargo ships; and arctic tankers. The last type, Ready Reserve Force ships, include roll-on/ roll-off ships; crane ships; lighterage-aboard ships, which function as floating barges and are critical for moving cargo ashore where infrastructure has been either damaged or destroyed or is non-existent; and aviation logistics support vessels.

Table 3. USN Platforms to Capability ComparisonOur evaluation of each of the USN and MSC vessel type in terms of its ability to conduct HADR missions is described in Tables 3 and 4. From these tables, we can identify those ships that have consistently high levels of capability with respect to HADR mission capabilities by identifying the rows of full circles (encircled in the tables). 
Table 4. MSC Platforms to Capability Comparison

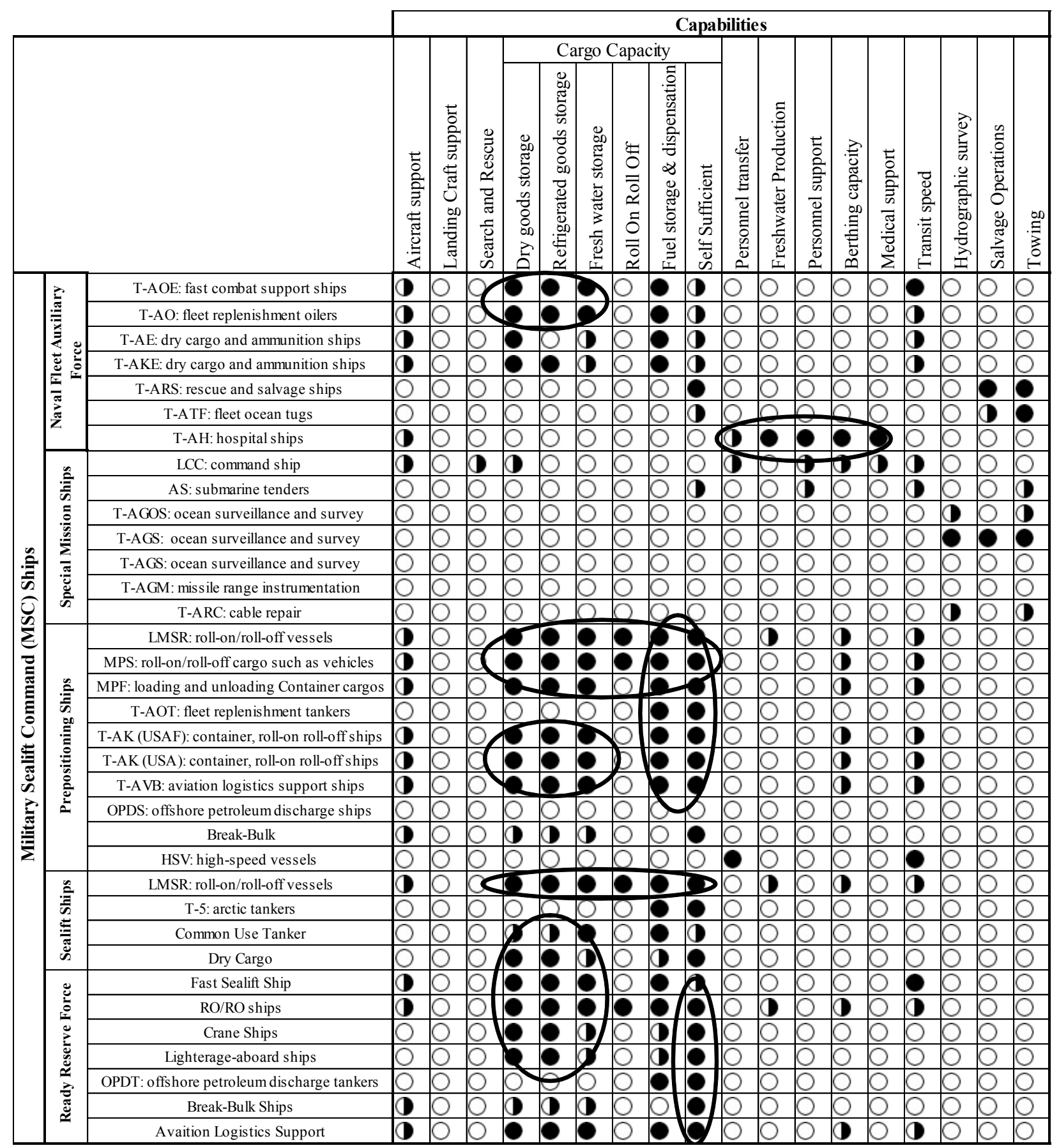

\section{OBSERVATIONS}

Our observations, based on the data collected and analyzed for the USN as well as on MSC assets, focus on timing capabilities in addition to the type of vessels deployed based on our synthesis of USN assets' suitability in HADR missions.

\subsection{USN Vessels}

The results of the ordinal ratings of ships to deliver HADR mission capabilities show that the USN (see Table 3) has significant cargo transfer capabilities as a result of the large numbers of helicopters and landing craft that may be deployed, the ability to bring large numbers of trained personnel to a disaster scene to assist with rescue, berthing space for temporary housing, and the large capacity to provide medical services. The amphibious assault ships 
have consistently high levels of capability to conduct HADR missions. Such ships may accommodate large numbers of helicopters as well as personnel and have medical and surgical capabilities aboard, to include operating rooms and a 1,000-unit blood bank. Additionally, amphibious assault ships have approximately 2,000 embarked Marines, who may be deployed to provide security and assistance to the affected area.

The limitations of cruisers, destroyers, patrol craft, and the littoral combat ship include a lack of storage and berthing facilities, insufficient medical services, lack of freshwater production or storage, and a lack of roll-on/roll-off capacity. In general, these ships are capable of traversing the oceans at high speeds but have very few of the other capabilities that are critical to HADR missions. The CRUDES-vessels that have embarked helicopters (cruisers, Flight IIA destroyers, and frigates)-may provide some aircraft support, such as search and rescue capability and personnel transfer capability. However, without an embarked helicopter, the CRUDES class of vessels is limited in their contribution to HADR missions.

\subsection{MSC Vessels}

The major advantage of the MSC fleet is its ability to carry large quantities of cargo to and from the disaster region (see Table 4). The MSC fleet also has two hospital ships that provide high levels of medical support as well as berthing capacity and the ability to produce freshwater. Although the MSC fleet has many desirable traits for HADR missions, it typically lacks embarked helicopters and is therefore marginally capable at conducting search and rescue missions or aircraft support. Another aspect of the MSC fleet is that the ships' crews are small, with the majority being civilian mariners. The small crews do not allow for a significant level of personnel support during HADR missions, and beyond the hospital ships, the MSC fleet does not have any capability to conduct medical support.

\subsection{Capabilities and Timing}

An important aspect of the understanding of the demand-supply picture is when the need arises and when it is fulfilled. In order to understand how USN HADR capabilities have been deployed in the past, as well as the types and levels of capability provided, we collected data about the on-scene arrival of every ship that was deployed to respond to the
Indian Ocean tsunami in 2004, Hurricane Katrina in 2005, and the Haiti earthquake in 2010.

Using the capability parameters given in Tables 3 and 4, we assigned each ship a capability value of 0 if it possessed little to no capability of performing a mission, a value of 1 if it had some capability, and a value of 2 if it was significantly capable of performing a mission. It is important to recognize that there is a great deal of difference between a ship with no landing craft support capability (0) and a ship with some capability (1). However, the difference between a ship with some capability (1) and a ship with significant capability (2) is much less.

We summed the capability values of all USN and MSC ships that were present on the scene during the disaster responses to arrive at a cumulative capability value for the HADR mission. The cumulative HADR capability value is a measure of the total of disaster relief capability that is on station in the disaster zone at a given time. Such measures of benefit rendered by a specific ship are in common use in the USN for certain primary events requiring specific force composition (Brown et al., 1989; Dugan, 2007; Hallmann, 2009; Silva, 2009). For instance, Brown et al. (1989) used the capability rating for the scheduling of ships for Atlantic Fleet combatants.

The cumulative capability offers an explanation of the total certain capabilities available (supply) for a given relief requirement (demand). For example, if only one ship was present during the disaster response and it had a mission capability of 1 for aircraft support, then the mission's cumulative capability for that day would be 1. If another ship were present with a mission capability score of 2 for aircraft support, then the mission's cumulative capability for that day would be 3 . Such cumulative capability for aircraft support aligns with the demand for search and rescue as well as distribution of critical commodities. We used cumulative capability for each day and each mission to analyze response patterns for all three disasters that are presented in Figures 5, 6, and 7. The cumulative capabilities include critical supplies aligning with demand for fuel, dry and refrigerated goods, freshwater production, and freshwater cargo. Transportation and rescue align with the need for aircraft support that in turn facilitates search and rescue, landing craft support, and personnel transfer. Medical and shelter care capability indicate providing for berthing capacity and medical support. In addition to these cumulative capability values depicting the fulfillment of relief requirements, timing of such delivery-which is of critical importance-is illustrated along a time line in Figures 5, 6, and 7. 


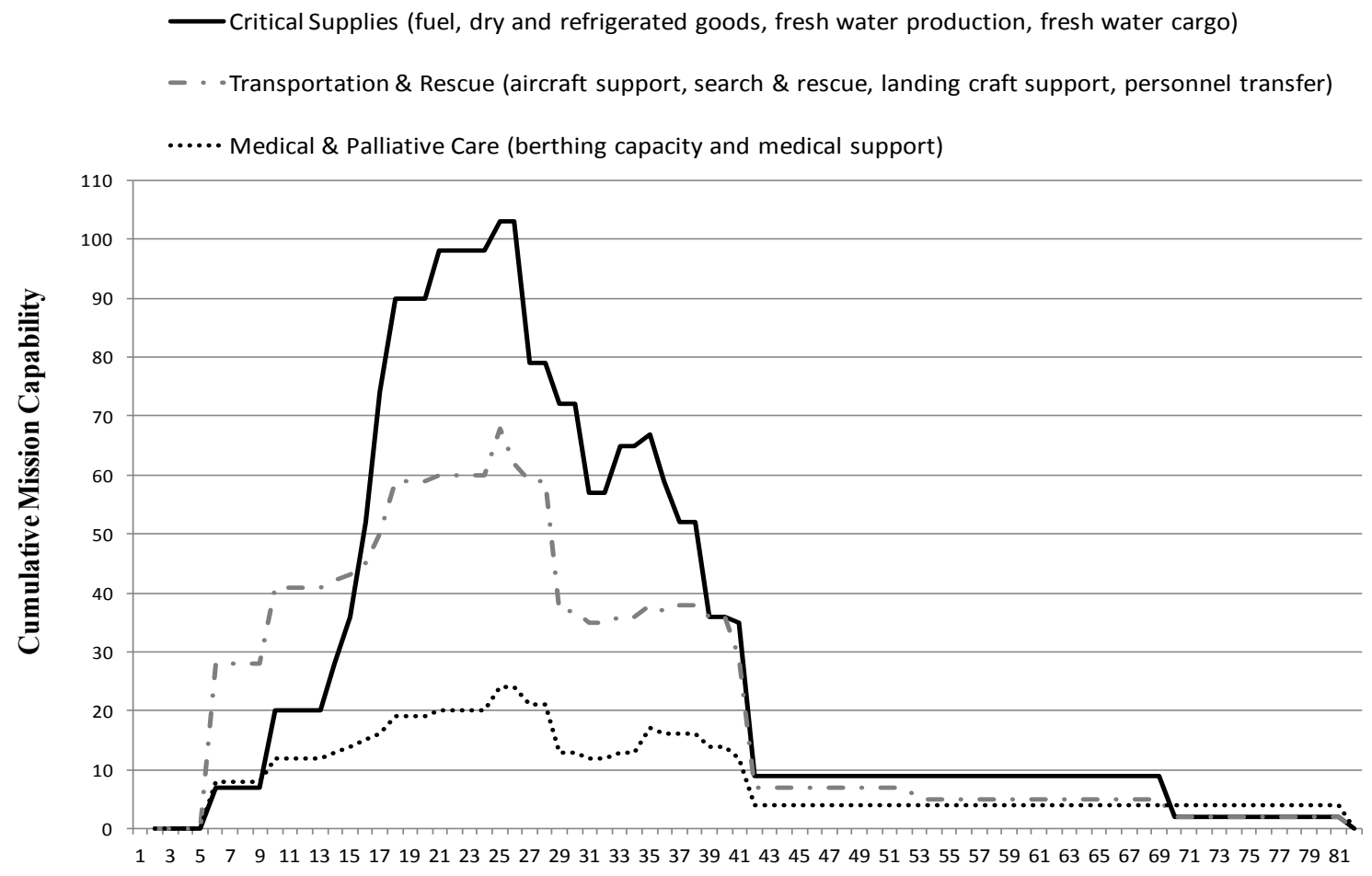

Day of Disaster Response

Figure 5. Cumulative Mission Capability for the Indian Ocean Tsunami

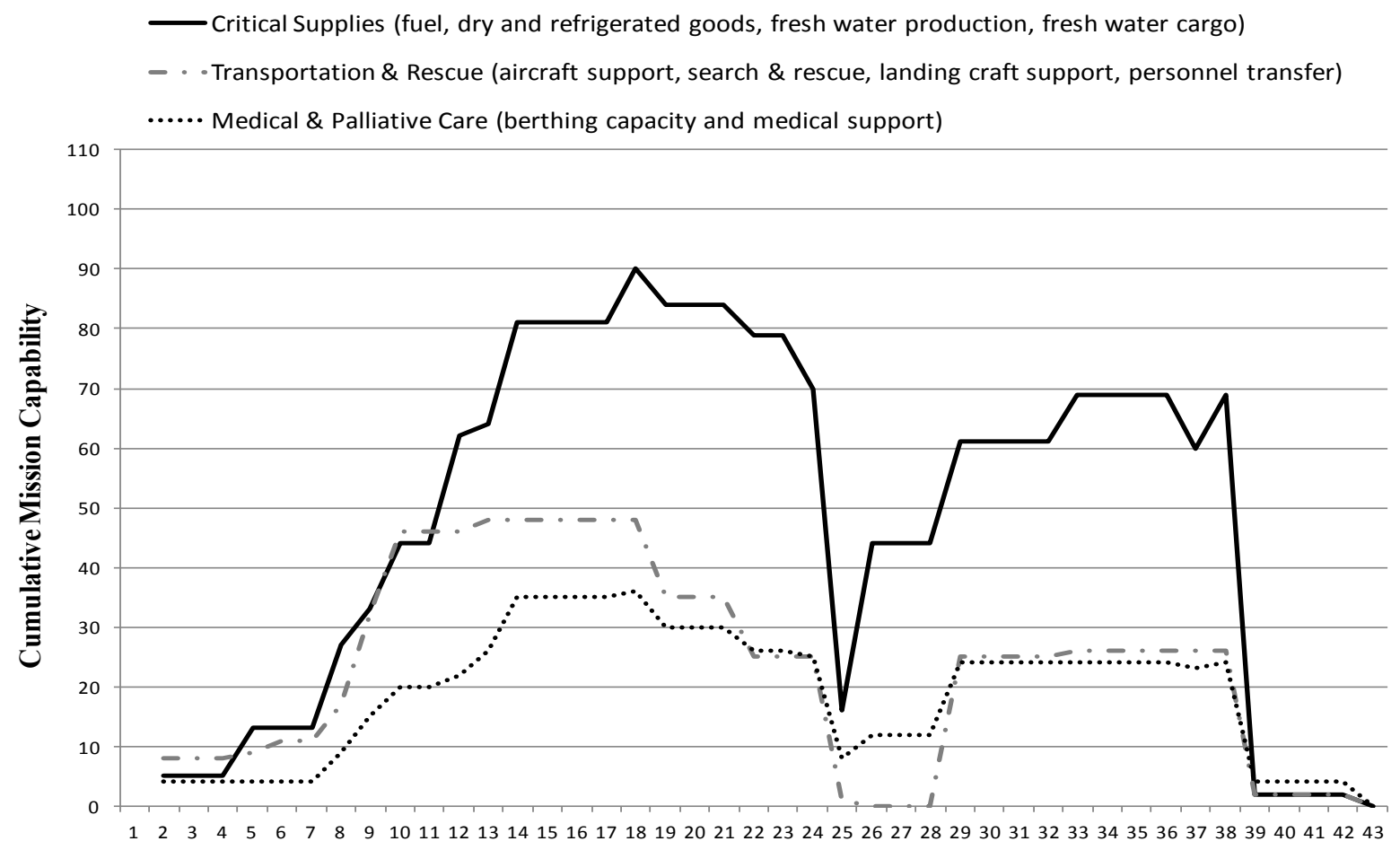

Day of Disaster Response

Figure 6. Cumulative Mission Capability for Hurricane Katrina 


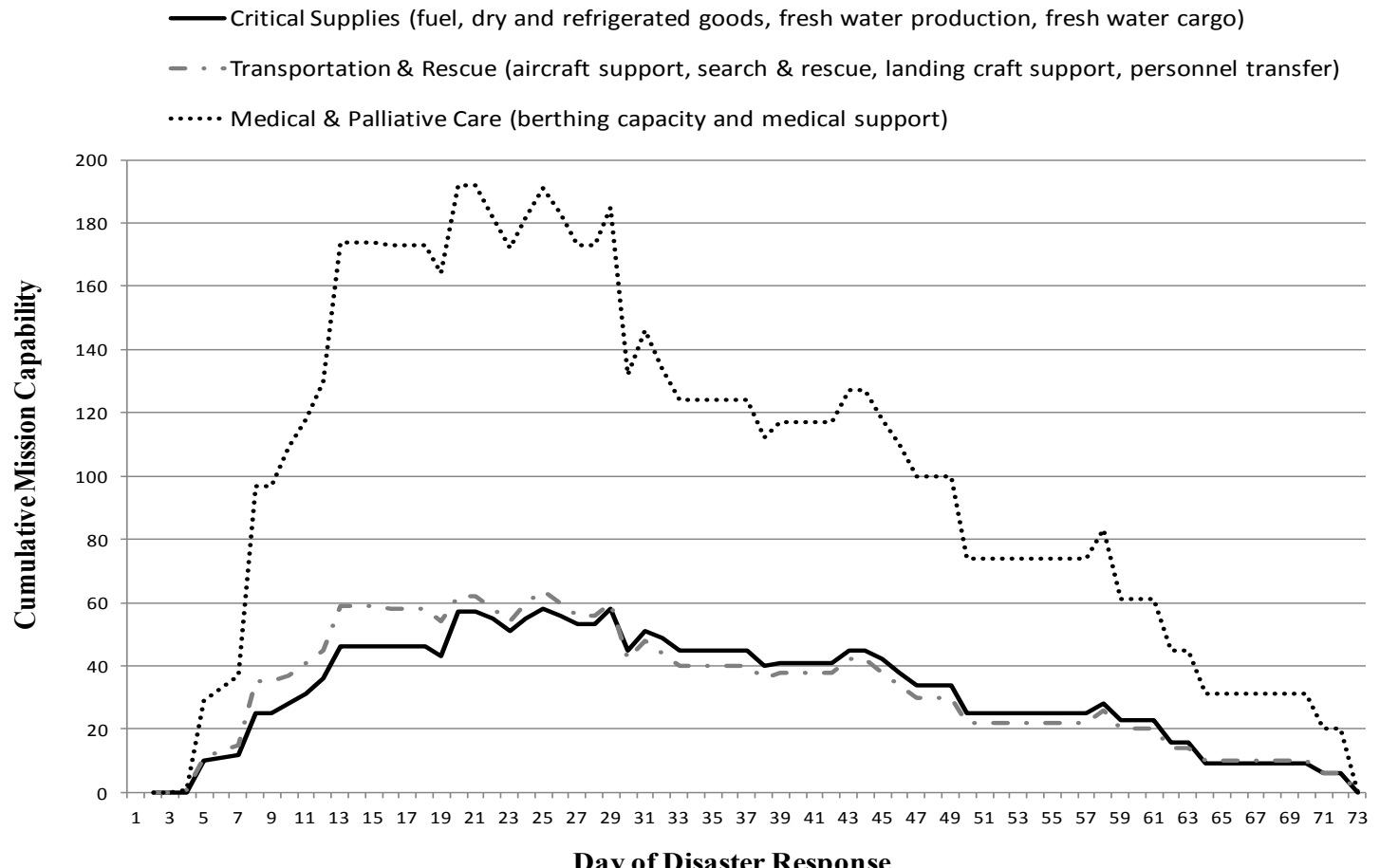

Figure 7. Cumulative Mission Capability for the Haiti Earthquake

\subsubsection{Indian Ocean Tsunami}

Table 5 shows that the response to the Indian Ocean tsunami lasted 81 days and that the first substantial increase in cumulative capability occurred two weeks into the effort. The peak of cumulative capability occurred on Day 24 of the response effort, and the peak range of support occurred from Day 15 to Day 35. Our data suggested that providing critical supplies was the mission that received the most support.

Table 5. Summary of the Response to Disasters

\begin{tabular}{|c|c|c|c|c|c|c|}
\hline \multirow{2}{*}{ Disaster } & \multicolumn{2}{|c|}{ Response } & \multicolumn{2}{|c|}{ Peak of Cumulative Capability } & \multirow{2}{*}{$\begin{array}{l}\text { Missions Receiving } \\
\text { the Most Support }\end{array}$} & \multirow{2}{*}{$\begin{array}{c}\text { Missions Receiving } \\
\text { the Least Support }\end{array}$} \\
\hline & Range & Completion & Range & Occurred & & \\
\hline $\begin{array}{c}\text { Indian Ocean } \\
\text { Tsunami } \\
\end{array}$ & 81 Days & Day 41 & Day 15 - Day 35 & Day 24 & $\begin{array}{c}\text { Provision of Critical } \\
\text { Supplies }\end{array}$ & $\begin{array}{c}\text { Medical Care and } \\
\text { Shelter } \\
\end{array}$ \\
\hline $\begin{array}{c}\text { Hurricane } \\
\text { Katrina }\end{array}$ & 42 Days & Day 38 & Day 10 - Day 23 & Day 17 & $\begin{array}{c}\text { Provision of Critical } \\
\text { Supplies }\end{array}$ & $\begin{array}{c}\text { Medical Care and } \\
\text { Shelter }\end{array}$ \\
\hline $\begin{array}{c}\text { Haiti } \\
\text { Earthquake }\end{array}$ & 72 Days & Day 41 & Day 12 - Day 28 & Day 19 & $\begin{array}{c}\text { Medical Care and } \\
\text { Shelter }\end{array}$ & $\begin{array}{l}\text { Provision of Critical } \\
\text { Supplies }\end{array}$ \\
\hline
\end{tabular}

\subsubsection{Hurricane Katrina}

The response to Hurricane Katrina lasted 42 days, and the first substantial increase in cumulative capability occurred two weeks into the effort. All USN and MSC support for the response was complete by Day 38. The peak of cumulative capability of the response occurred on Day 17 of the response effort, and the peak range of support occurred from Day 10 to Day 23.

\subsubsection{Haiti Earthquake}

The USN response to the Haiti earthquake lasted 72 days. Nearly all USN and MSC support for the response effort was complete by Day 41 . The first substantial increase in cumulative capability occurred two weeks into the effort. The peak cumulative mission composite capacity of the response occurred on Day 19 , and the peak range of support occurred from Day 12 to Day 28. 


\subsection{Summary of Disaster Responses}

The USN fleet is composed of carrier strike groups, expeditionary strike groups, amphibious ready groups, and submarine strike groups. These organizational structures were conceived in order to be effective in major war campaigns; however, they do not appear to be the best formations of vessels for responding to HADR operations. Our data show that the smallest number of ships used in any of the three disaster responses discussed was 29, and the largest was 34 .

Studying the details of the three missions, critical supplies, transportation and rescue, and medical and shelter, we observed that in the case of the 2004 Indian Ocean tsunami, the USN deployed full expeditionary strike groups, which resulted in tasking several CRUDES vessels to support the HADR mission. CRUDES vessels provide little assistance in HADR operations and, therefore, were being underutilized for their entire time on station.

\subsection{Cumulative Mission Capability}

Figure 8 illustrates the cumulative mission capability from all ships present in each HADR response. The graph shows that the USN and MSC provide significantly more cumulative capacity to HADR missions within two weeks of the event and then taper off on or just before the 40th day after the disaster event. Typically, support is ramped up in the first two weeks of a response and then begins to level out as it peaks, usually near the end of the third week.

We fitted the graph of average cumulative capability over the disasters with a Weibull probability distri- bution. Figure 8 shows the basic shape of the relationship between cumulative capability and time in a USN and MSC disaster response effort. The slope suggests a response reaching the highest peak by Day 19 and then tapering off. This general shape of USN and MSC support to HADR missions is consistent with Pettit and Beresford's (2005) model of emergency recovery that examined emergency relief operations in military and non-military circumstances. The relationship between the "when" of the demand and the supply indicates the gap of pain due to a lag in arrival of relief. However, it should be pointed out that the bulk of the core relief arrives relatively quickly, given the size of the fulfillment, and leaves fairly quickly.

\section{DISCUSSION}

The USN and MSC responses to the tsunami, hurricane, and earthquake were surprisingly consistent. One hospital ship was used in each of the disaster responses. More MSC vessels were sent to each disaster than USN vessels. The number of amphibious assets employed was usually much larger than CRUDES. The one instance where more CRUDES were sent than amphibious ships was when the USN deployed an entire carrier strike group. However, since the 2004 tsunami, seemingly, the USN has adopted a joint task force approach to HADR missions. One conclusion that can be drawn from the mission response data represented in Figure 8 is that the USN and MSC typically arrive en masse two weeks into a response effort and provide peak capability during the third week. The relief rapidly declines as vessels are withdrawn during the close of an operation.

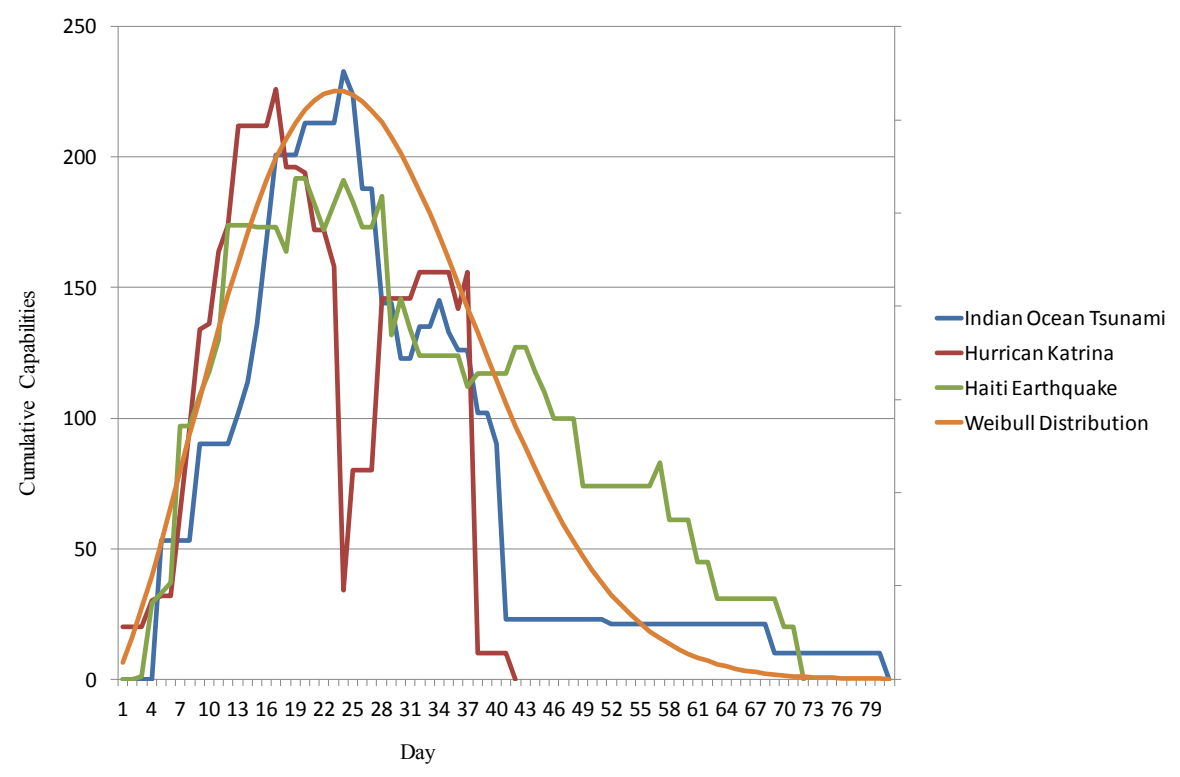

Figure 8. Cumulative HADR Capabilities for the Three Disasters 
It is true that the degree of uncertainty that exists in both the disaster environment and the requirements associated with alleviating its effects greatly complicates the planning and response process. Based upon our analysis of HADR capabilities, we believe that task force composition, force structure, and design of USN and MSC HADR responses need to be robust with respect to both the environment and the requirements for assistance. Tables 4 and 5 suggest which vessels have the greatest utility when conducting HADR missions, and what combination of vessels are required to cover the full range of missions that HADR operations require. Our analysis indicates that amphibious vessels typically have the greatest utility with respect to conducting HADR operations due to their embarked helicopter capabilities, landing craft, and berthing and medical capacity. Our analysis has also shown the limitations of specific USN vessels when it comes to conducting the full range of HADR missions. In addition, the analysis validated that those vessels which can conduct lift operations are best suited to conduct HADR missions. Vessels that can provide personnel to assist in disaster response, and provide medical services, are also of great utility. However, those vessels that are limited in their ability to conduct such missions are not well suited for HADR missions.

We believe that for future HADR operations, a HADR task force composed of amphibious vessels and MSC vessels will be more effective and efficient. A task force should be able to conduct all required HADR missions with only the most effective platforms, leaving other vessels free to perform other USN missions or training. Based on Tables 4 and 5, we identified the specific vessel (classes) best suited for HADR operations that are supported by their respective capabilities. These are as follows: We believe that amphibious assault and transport dock ships need to be part of the "HADR flotilla" because of their ability for search and rescue, aircraft and landing support, freshwater production, berthing capacity, and medical support. Although nuclearpowered aircraft carriers have the ability to provide aircraft support, freshwater production, berthing capacity, and medical support, these vessels primarily support fixed-wing fighter aircraft that do not have the same level of utility as vertical lift and rotarywing aircraft, which are abundant on amphibious assault ships. Combat ships such as destroyers and cruisers can travel at high speeds, and they have very little utility in the disaster zone because they lack the ability to produce large amounts of freshwater, do not have excess food stores, and generally lack extra berthing capacity. These ships are particularly illsuited to HADR missions if, in addition, they lack an embarked helicopter. The oilers, prepositioning ships with roll-on/roll-off capability, and hospital ships can also be elements of an HADR flotilla because they have storage capacity and capabilities that other commercial ships and warships lack.

The response to Hurricane Katrina provides an obvious caveat to our proposed force structure for HADR operations. The presence of nine mine countermeasures vessels in the Gulf of Mexico were capable of locating and corralling oil rigs that had broken free and were drifting in open water (United States Northern Command, 2005). Another special consideration in HADR operations-based on the 2011 Japan earthquake - is the use of nuclear-reactor-qualified personnel in gaining stability to the affected reactors, a very unique situation in which the USN played a vital role in assisting the affected population.

\section{CONCLUSION}

Providing appropriate HADR requires an understanding of the needs of the affected population. In this research, we proposed a list of general relief requirements (demand) based on representative disasters. We described the capabilities of the USN and MSC as suppliers of relief in disasters. Additionally, we illustrated the response time of the supply of relief. We identified the primary mission requests received by the USN and MSC and then rated each HADR mission capability provided by every ship in the USN and MSC. We used the mission capabilities for each ship and combined them with the time line of every ship deployed for each of the disasters we studied. Based upon the relief capability and response time, we calculated a cumulative capability that constitutes an index of the relative HADR mission capability for a disaster response in a particular time window.

The USN provides substantial HADR due to its unique capabilities. Our analysis in this research contributes to a firmer understanding of which vessels are most appropriate for use during disaster response. We believe our methodology may be used as a template by other military organizations that have missions to support humanitarian operations, such as NATO or the MCDA. Studies of this nature may expose the issue of relief requirements in terms 
of "what" and "when" for the organizations with assets similar to the USN. Such military organizations can make more effective decisions when considering the types of vessels they will procure in the future as well as in planning and executing humanitarian operations throughout the world. This is important in reducing the gap of pain since needs assessment is a critical issue, which, due to its complexity, has not been adequately studied.

Understanding capabilities facilitates the planning of humanitarian operations, especially when diverse organizations participate in the disaster relief. Such understanding facilitates the relief operations thus directly influencing the welfare of the affected population in the society. Similar evaluations of resources and the capabilities of organizations that are significant players in humanitarian operations, such as UNICEF, CARE, WFP, and Fleet-Forum, will help to identify which organizations are capable of providing what type of relief and where. Since we believe that understanding the capabilities of these organizations will develop a richer picture of humanitarian operations and effort, our research for one such organization, the USN, sets the stage for the evaluation of other organizations. This is the first step in that direction. In this vein of research other researchers can pursue similar studies to further this research by continuing the evaluation process described for disaster response capabilities.

Future research may involve the development of an optimization model to determine an appropriate "product mix" of vessels for disaster response. Such a model would determine the optimal mix of ships based on capabilities, as opposed to the proximity or availability of a ship. The model currently being developed is as follows: the objective is to reduce the gap of pain (by maximizing the available capabilities for relief requirements). The constraints result from issues such as budget/cost, availability of personnel, and operational abilities.

\section{REFERENCES}

Apte, A. 2009. "Humanitarian logistics: A new field of research and action", Foundations and Trends in Technology, Information and Operations Management, Vol. 3(1):1-99.

Apte, A. and Yoho, K. 2011. “Capabilities and competencies in humanitarian operations", paper presented at the 18th European Operations Management Association (EurOMA) Conference.

Aymat, J. 2010. “Operation unified response: Joint task forceHaiti, D+37 brief", unpublished PowerPoint briefing, Naval War College, Newport, RI.
Baker, S.F., Morton, D.P., Rosenthal, R.E. and Williams, L.M. 2002. "Optimizing military airlift", Operations Research, Vol. 50(4):582-602.

Balcik, B., Beamon, B.M., Krejci, C.C., Muramatsu, K.M. and Ramirez, M. 2010. "Coordination in humanitarian relief chains: Practices, challenges and opportunities", International Journal of Production Economics, Vol. 126(1):22-34.

Barbarosoglu, G., Ozdamar, L. and Cevik, A. 2002. “An interactive approach for hierarchical analysis of helicopter logistics in disaster relief operations", European Journal of Operational Research, Vol. 140(1):118-133.

Brown, G., Goodman, C. and Wood, K. 1989. “Annual scheduling of Atlantic Fleet naval combatants", Operations Research, Vol. 38(2):249-259.

Commander, Navy Installation Command (CNIC) 2012. available at: http://www.mors.org/UserFiles/file/meetings/07avi/ dunn-3.pdf.

Congressional Research Service (CRS) 2005. Hurricane Katrina: DoD disaster response. RL33095, available at: http://www.fas.org .

Cuculo, A. 2006. “National response to catastrophic events: Applied lessons for consequence management", PowerPoint briefing presented at the meeting of Joint Center for Operational Analysis, Colorado Springs, CO.

Day, J.M., Melnyk, S., Larson, P., Davis, E. and Whybark, D.C. 2012. "Humanitarian and disaster relief supply chains: A matter of life and death", Journal of Supply Chain Management, Vol. 48(2):21-36.

Department of the Navy (DoN) 2010. Naval operations concept, Implementing the maritime strategy, available at: http://www. navy.mil/maritime/noc/NOC2010.pdf

Dugan, K. 2007. Navy Mission Planner, master's thesis, Naval Postgraduate School, Monterey, CA.

Elleman, B.A. 2007. Waves of Hope: The U.S. Navy's Response to the Tsunami in Northern Indonesia, Naval War College Press, Newport, RI.

EM-DAT 2011. "The international disaster database", available at: http://www.emdat.be/database

Freedberg, S. J. 2012. Former CNO, DepDevDef Fight to Stop Cuts to Navy's Humanitarian Mission. Sea. Retrieved from http://defense.aol.com/2012/06/04/hamre-roughead-fight-tosave-navys-humanitarian-mission-from-c/

Guilloux, A. 2011. “Disaster Response Mechanism: In Search of a More Effective System", World Politics Review, available at: http://www.worldpoliticsreview.com/articles/9588/disasterresponse-mechanisms-in-search-of-a-more-effective-system

Hale, T. and Moberg, C.R. 2005. "Improving supply chain disaster preparedness: A decision process for secure site location", International Journal of Physical Distribution \& Logistics Management, Vol. 35(3):195-207.

Hallmann, F. 2009. Optimizing Operational and Logistical Planning in a Theater of Operations, master's thesis, Naval Postgraduate School, Monterey, CA. 
Inspector General, U.S. Department of Homeland Security 2006. Management advisory report on the acquisition of cruise ships for Hurricane Katrina evacuees. GC-HQ-06-11, available at: http:// www.dhs.gov/xoig/assets/katovrsght/OIG_GC_HQ 06-11.pdf.

Jane's 2010. Jane's Fighting Ships: The authority on the world's navies, available at: $\underline{\text { http://jfs.janes.com/public/jfs/index.shtml }}$

Louisiana Department of Health and Hospitals (2006).

McCoy, J.H. 2008. “Humanitarian response: Improving logistics to save lives", American Journal of Disaster Medicine, Vol. 3(5):283-293.

Miles, D. 2011. “Pacific Mission Tests Disaster Response Capabilities", American Forces Press Services, available at: http://www. defense.gov/News/NewsArticle.aspx?ID=62996

Military Sealift Command (MSC) 2010. The U.S. Navy's Military Sealift Command Handbook 2010, Author, Washington Navy Yard, Washington, DC.

Moroney, J. D. P., Pezard, S., Miller, L. E., Ergstrom, J. G., and Doll, A. 2013. “Lessons from DoD Disaster Relief Efforts in the Asia-Pacific Region", available at: http://www.rand.org/ content/dam/rand/pubs/research_reports/RR100/RR146/ RAND RR146.pdf

National Oceanic Atmospheric Administration Public Affairs 2007. "Hurricane Katrina", available at: http://www.katrina. noaa.gov

Pettit, S.J. and Beresford, A.K. 2005. "Emergency relief logistics: An evaluation of military, non-military and composite response models", International Journal of Logistics: Research and Applications, Vol. 8(4):313-331.

Plyer, A. 2010. "Facts for features: Hurricane Katrina impact", press release, available at: http://www.gnocdc.org/Factsforfeatures/HurricaneKatrinaImpact/index.html
Schulte, A. 2010. "Henson clears path for Haiti”, Sealift, available at: http://www.msc.navy.mil/sealift

Semilla, F. 2011. Contingency Operations Officer, Pacific Fleet, United States Navy. Personal communication.

Silva, R.A. 2009. Optimizing Multi-Ship, Multi-Mission Operational Planning for the Joint Force Maritime Component Commander, master's thesis, Naval Postgraduate School, Monterey, CA.

United States Northern Command 2005. USNORTHCOM Hurricane Katrina Timeline - Draft, available at: http://www.northcom.mil/FOIA

VanRooyen, M., \& Leaning, J. 2005. After the tsunami-Facing the public health challenges. New England Journal of Medicine, 352, 435-438. Retrieved from http://www.nejm.org

Vos, F., Rodriguez, J., Below, R. and Guha-Sapir, D. 2009. Annual Disaster Statistical Review 2009: The Numbers and Trends, Centre for Research on the Epidemiology of Disasters, Brussels, Belgium.

Whybark, D.C. 2007. “Issues in managing disaster relief inventories", International Journal of Production Economics, Vol. 108(12):228-235.

Wooldridge, M. 2010. "Haiti will not die, President Rene Preval insists", available at: http://news.bbc.co.uk/2/hi/americas/8511997.stm

Yi, W. and Ozdamar, L. 2007. "A dynamic logistics coordination model for evacuation and support in disaster response activities", European Journal of Operational Research, Vol. 179: 1177-1193.

Xinhua 2013. "State Counselor urges improving disaster relief capabilities", Global Times, 2013-5-12, available at: http:// www.globaltimes.cn/content/780954.shtml\#.UkG7ioasim4 


\section{AUTHOR'S BIOGRAPHY}

Aruna Apte, Naval Postgraduate School, is an Associate Professor at the Naval Postgraduate School in Monterey, California. She has more than 20 publications in peer-reviewed academic journals such as Interfaces, Naval Research Logistics, Production and Operations Management, a monograph in Humanitarian Logistics and one patent. Currently her research is focused in humanitarian and military logistics and she advises emergency planners in preparing for disaster response. She served as the president for Humanitarian Operations and Crisis Management College in the Production and Operations Management Society. Aruna received her Ph.D. in Operations Research from Southern Methodist University in Dallas.

Keenan D. Yoho, Naval Postgraduate School, is an Assistant Professor at the Naval Postgraduate School in Monterey, California. Dr. Yoho His primary research focus is on the allocation of resources under conditions of uncertainty and scarcity. Recent areas of focus have been on supply chain management, military special operations, and humanitarian assistance and disaster response. Keenan earned his Ph.D. in Operations Management, an M.B.A. in Operations and Information Management, and a M.S. in Industrial Relations from the University of Wisconsin-Madison as well as an undergraduate degree in Religion from Temple University.

Cullen M. Greenfield, United States Navy, is a Surface Warfare Officer in the United States Navy. Cullen has served several tours on surface warfare vessels to include Chief Engineer on the U.S.S. Tortuga. Cullen earned his Master's of Business Administration at the Naval Postgraduate School.

Cameron A. Ingram, United States Navy, is a Surface Warfare Officer (SWO) in the United States Navy. Cameron was commissioned in June of 2004 after graduating from the U.S. Merchant Marine Academy in Kings Point, NY. He has served onboard two guided missile destroyers the USS HOPPER (DDG 70) and the USS MITSCHER (DDG 57). Cameron earned his Master's of Business Administration at the Naval Postgraduate School. 